\title{
Gobernanza de transporte en áreas metropolitanas: revisión crítica y análisis para Santiago de Chile
}

Clemente Larraín-Videla. Centro de Estudios Públicos, Santiago, Chile. Juan-Carlos Muñoz. Pontificia Universidad Católica de Chile, Santiago, Chile. Julio Briones. Pontificia Universidad Católica de Chile, Santiago, Chile.

RESUMEN | Para abordar los desafíos de movilidad en las áreas metropolitanas, se ha cuestionado la institucionalidad política y territorial desde donde se planifica, invierte y gestiona el transporte y desarrollo urbano. En este trabajo se realiza una evaluación y revisión crítica del efecto de la gobernanza en las políticas de transporte en áreas metropolitanas, considerando los grados de integración entre las agencias públicas y la distribución de poder y competencias en los diferentes niveles de gobierno. Luego, se propone una metodología que permite caracterizar una gobernanza de transporte urbano. Aplicando esta metodología a Santiago de Chile, se observa: i) una centralización del poder y competencias; ii) dispersión y especialización de funciones; y iii) fragmentación del territorio. El marco de análisis propuesto puede ser útil para descomponer y comparar los diseńos institucionales metropolitanos y reconocer reformas que mejoren el desempeño de las políticas de transporte.

PALABRAS CLAVE | transporte urbano, áreas metropolitanas, reestructuración territorial.

ABSTRACT | To approach the mobility challenges in metropolitan areas, we question the territorial and political institutional framework of recent decades. This work makes an evaluation and critical review of the governance effect in transport policies, considering the degrees of integration between public agencies and the distribution of power and competencies at different levels of government. The article proposes a methodology to characterize the urban transport governance. When this methodology is applied to Santiago de Chile, we observe: i) centralization of power and competences, ii) dispersion and specialization of functions, and iii) fragmentation of the territory. This analysis framework is useful to analyze and compare metropolitan institutional designs and recognize possible reforms that improve the performance of transport policies.

KEYWORDS | urban transportation, metropolitan areas, territorial restructuring. 


\section{Introducción}

Desafíos de movilidad en las áreas metropolitanas latinoamericanas

Los países latinoamericanos han vivido intensos procesos de urbanización en las últimas décadas. Este crecimiento urbano se ha concentrado en las grandes ciudades y se ha caracterizado por su dispersión y periurbanización, es decir, por un crecimiento más allá del área tradicionalmente urbanizada (Cruz-Muñoz, 2021; De Mattos, 2001; Heinrichs et al., 2009). Es así como se utiliza con cada vez más frecuencia el término "áreas metropolitanas", para referirse también a aquellas zonas urbanizadas dependientes de la ciudad central (Rodríguez \& Oviedo, 2001).

La transformación señalada ha impactado la configuración y movilidad urbana, con crecimientos significativos en la tasa de motorización, número de viajes, uso del automóvil y niveles de congestión (Figueroa, 2005; Monzón, 2005; Moscoso et al., 2020). A ello se suma la segregación social y de usos de suelo, que ha favorecido el aumento de la longitud promedio de los viajes, en particular para la población de menores ingresos (Suazo-Vecino et al., 2020). Por otra parte, las áreas metropolitanas se han transformado en un espacio clave para enfrentar el cambio climático, recibiendo especial atención en los Objetivos de Desarrollo Sostenible (ods) de las Naciones Unidas.

Este escenario presenta una serie de desafíos para la planificación del transporte y su integración con el desarrollo urbano: disminuir tiempos de traslado y emisiones de carbono, mejorar la accesibilidad y asequibilidad a las oportunidades de la ciudad y promover la integración social y la habitabilidad. Para enfrentar estas tareas, se han propuesto y discutido diversas acciones y políticas urbanas y de transporte. Sin embargo, también existe otro plano de discusión, centrado en la institucionalidad política y territorial que se requiere para abordar adecuadamente esos desafíos; es decir, la organización del gobierno de las ciudades (Sánchez, 2008). Esta dimensión ha sido denominada "gobernanza de las áreas metropolitanas", y pone su foco principalmente en el diseño normativo, político e institucional y en las relaciones de poder e intereses de los diferentes actores.

\section{Gobernanza metropolitana de transporte: discusiones conceptuales y metodológicas}

La gobernanza como objeto de estudio excede los estudios urbanos, y tiene sus variantes en la ciencia política y la economía institucional. De acuerdo con Jaimurzina (2018) y Sánchez (2008), los conceptos de gobernanza que atraviesan la literatura se podrían clasificar en dos categorías generales. En primer lugar, se encontraría la gobernanza en su sentido "clásico", basado en la teoría organizacional, y que abarca la relación entre los diferentes actores que la constituyen y cómo estos se ven afectados en diferentes marcos institucionales. Luego, se encontraría una concepción de gobernanza más reciente, que estudia la relación de los gobiernos con una diversidad de actores externos (sociedad civil y participación ciudadana) en un escenario de fragmentación del poder.

En la literatura sobre gobernanza de áreas metropolitanas, ambas perspectivas están presentes. Desde la gobernanza en su sentido clásico, existe un amplio 
campo de estudio sobre los modelos institucionales adecuados para gobernar las áreas metropolitanas, que ofrece una justificación teórica y empírica de la necesidad de una escala metropolitana para planificar y gestionar adecuadamente las ciudades (Lefèvre, 1998; Organisation for Economic Co-operation and Development [OECD], 2015; Rojas et al., 2005; Yáńez, 2008). Dentro de este campo, se utiliza comúnmente la mirada de gobernanza multinivel, introducida por Hooghe y Marks (2001), que distingue las actividades de gobierno en sus distintos niveles (local, metropolitano, regional, nacional, supranacional). Por otra parte, desde una perspectiva de gobernanza como fragmentación del poder, se han estudiado las dificultades que tiene la institucionalidad política metropolitana para articularse e incorporar a las organizaciones y movimientos sociales (Heinelt, 2004; Klein \& Tremblay, 2010; Kübler \& Heinelt, 2004; Sagaris \& Landon, 2017).

Lo mismo ocurre en la literatura sobre gobernanza de transporte, donde las perspectivas utilizadas y los objetos de estudio son diversos. Jaimurzina (2018), en una extensa revisión bibliográfica, muestra cómo estas investigaciones suelen focalizarse en áreas específicas de las políticas de transporte (tales como puertos, autopistas, smart mobility, entre otros), observando una toma decisiones cada vez más compleja a causa de hechos recientes e interrelacionados, como la fragmentación del poder, el cambio climático, las dificultades intersectoriales o los avances tecnológicos.

En definitiva, existe una acotada literatura que aborda la gobernanza de la movilidad con un enfoque metropolitano. Las investigaciones que se ocupan del transporte en áreas metropolitanas suelen enfocarse en las políticas necesarias para la planificación y gestión de la movilidad, pero no examinan la institucionalidad política y territorial que las sostienen. Marsden y Reardon (2017), en un metaestudio en revistas académicas de políticas de transporte, reconocen una brecha entre esta literatura y los tomadores de decisión, afirmando que "para entender y avanzar en el estado del arte de las políticas de transporte, es necesario incorporar preguntas sustantivas de gobernanza que pongan mayor atención al contexto, la política, el poder, los recursos y la legitimidad" (p. 249, traducción propia).

En cualquier caso, existen autores y trabajos relevantes que abordan la gobernanza metropolitana de transporte y que son ineludibles para formular preguntas de investigación. Una primera referencia corresponde a los trabajos de GiménezCapdevilla (2005, 2008), quien, utilizando el marco de gobernanza multinivel, profundiza en las responsabilidades de distintas escalas de gobierno -especialmente la regional y la metropolitana- en las políticas de transporte. Para ello, analiza los diseños institucionales y territoriales de algunas ciudades y regiones europeas, evaluando los efectos de la distribución de competencias, instrumentos y recursos en la planificación y regulación del transporte. Por otra parte, se tiene los trabajos de Rode et al. (2008) y Rode (2019), de LSE Cities, que realizan un aporte significativo para comprender la relación entre gobernanza y planificación integrada. Con tal fin realizan un análisis comparativo de varias metrópolis del mundo, utilizando métodos cualitativos para reconocer los arreglos institucionales subyacentes. Estos trabajos sugieren que la gobernanza del transporte urbano debe promover su integración con la planificación del suelo y las actividades. 
En tercer lugar, se tienen los trabajos de Veeneman et al. (2015) y Veeneman y Mulley (2018), cuyo foco está en la gobernanza del transporte público desde una perspectiva multinivel y del federalismo fiscal. En ambos se analiza la relación entre la institucionalidad y la provisión de transporte público a través de la estructura presupuestaria de los diferentes niveles de gobierno. Finalmente, se tiene el extenso trabajo de Busetti (2015), donde analiza directamente la gobernanza metropolitana de transporte. A través de ejercicios teóricos, revisiones bibliográficas y análisis de casos, cuestiona lo que llama "lógica instrumental", según la cual existiría una relación causal entre los diseños institucionales y el desempeño de las políticas de transporte. Sugiere entonces complejizar los análisis, para comprender el comportamiento de las agencias bajo diferentes normativas y escenarios.

\section{Objetivos y limitaciones de la investigación}

En este contexto, el propósito de este trabajo es contribuir al estado del conocimiento sobre la gobernanza de transporte en áreas metropolitanas. Para ello, se proponen dos preguntas de investigación: una teórica y otra contextualizada a la realidad latinoamericana.

En primer lugar, se profundizará en cómo los diferentes diseños institucionales inciden en las políticas de transporte urbano, sistematizando la experiencia existente. Para ello, en línea con las sugerencias de Rode et al. (2008) y Rode (2019), se analizarán las consecuencias que tienen los grados de integración ${ }^{1}$ de las agencias públicas en las políticas de transporte y de planificación del suelo. Por otra parte, se utilizará un esquema de gobernanza multinivel equivalente al propuesto por Giménez-Capdevilla (2005, 2008), para evaluar los efectos que tiene en las políticas de transporte la distribución del poder y competencia entre diferentes escalas de gobierno. Para ambos casos, se propondrá una metodología que incorpora dimensiones y criterios de evaluación, a fin de evitar parte de la lógica instrumental sobre la cual alerta Busetti (2015).

En una segunda etapa, se caracterizará y analizará la gobernanza de transporte de Santiago de Chile, con el propósito de evaluar y validar las proposiciones teóricas en un área metropolitana concreta. Para ello, se propondrá una metodología que permita caracterizar su diseńo institucional, identificando las agencias públicas que participan y la distribución de poder y competencias. A partir de este ejercicio, se realizará una síntesis de las principales observaciones realizadas a la institucionalidad urbana y de transporte en Chile, articulándolas con el análisis desplegado en la primera sección. Finalmente, se presentará una discusión de todos los resultados, incluyendo los aportes y alcances de la investigación.

1 Los grados de integración entre agencias, de acuerdo con Stead y Meijers (2009), corresponde a cualquiera de estas formas de interacción: i) coordinación: flujos de información entre las agencias, manteniendo las acciones separadamente; ii) cooperación: relación formal entre las agencias, que implica algún grado de acción conjunta; iii) colaboración: acción conjunta y estructurada entre las agencias; y iv) integración efectiva: relación estructurada entre agencias, que reconoce las consecuencias conjuntas, evalúa perspectivas globales e involucra distintos niveles de políticas. Estos grados de integración constituyen una pirámide jerárquica, donde un grado mayor siempre incorpora las formas de relación anteriores. 
Por cierto, este trabajo presenta algunas limitaciones importantes. En primer lugar, carece de una profundización sustantiva respecto de la articulación entre la gobernanza de transporte y la sociedad civil. La perspectiva de gobernanza utilizada es más bien la considerada clásica, por lo que el foco no está en el rol de la institucionalidad de transporte ante la dispersión del poder y el empoderamiento de la ciudadanía. Sin duda se requieren otros trabajos para profundizar y comprender cómo la gobernanza de transporte en áreas metropolitanas puede incorporar de forma efectiva y democrática a las comunidades y organizaciones.

Luego, este trabajo asume que las agencias públicas son estáticas, y no estudia su comportamiento individual ante cambios normativos y escenarios cambiantes. Como también alerta Busetti (2015), las agencias públicas que conforman la institucionalidad política y territorial siempre pueden comportarse de una manera diferente a como propone el diseño. Para ello, el mismo autor propone considerar los incentivos y las sanciones que determinan las acciones de los agentes, o la jerarquía entre los agentes y la asimetría de sus posiciones, lo que podría ser abordado en futuras investigaciones a partir de análisis de casos.

\section{Metodología}

En una primera parte, con el propósito de comprender y analizar la incidencia de los diseños institucionales en las políticas de transporte urbano, se realizó una revisión bibliográfica, organizada a partir de cinco criterios de evaluación: eficiencia, equidad, coherencia, legitimidad y accountability. Estos criterios, basados en el trabajo de Slack (2007), evalúan los servicios públicos en dimensiones que pueden ser afectadas tanto por la distribución de competencias entre las distintas escalas de gobierno, como por la integración o independencia de las agencias públicas. De esta forma, la evaluación de los diseños institucionales desde distintas perspectivas evita la simplificación del análisis y permite una comprensión más integral de cómo impactan en las políticas de transporte.

La Tabla 1 describe los cinco criterios. Por cierto, los conceptos propuestos son más bien generales y están interrelacionados; sin embargo, su objeto no es entregar definiciones excluyentes, sino que, de forma conjunta, permitir un marco de observación y comparación para los análisis posteriores.

TABLA I | Criterios de evaluación

\begin{tabular}{|l|l|}
\hline \multicolumn{1}{|c|}{$\begin{array}{c}\text { CRITERIO DE } \\
\text { EVAluaCión }\end{array}$} & \multicolumn{1}{c|}{ DETALLE } \\
\hline Eficiencia & Efectividad para conseguir los objetivos propuestos \\
\hline Equidad & Promoción de la igualdad de todos los ciudadanos \\
\hline Coherencia & Congruencia y grado de complementariedad con otras políticas \\
\hline Legitimidad & Aceptación social y nivel de participación de la ciudadanía \\
\hline Accountability & Rendición de cuentas y responsabilidad por los resultados \\
\hline
\end{tabular}

FUENTE: ELABORACIÓN PROPIA A PARTIR DE SLACK (2007) 
En una segunda parte, con el objetivo de caracterizar el diseño institucional en torno a las políticas de transporte en Santiago de Chile, se utilizó una metodología que permite esquematizar y descomponer la gobernanza de transporte de un área metropolitana. Dentro de ella se considera también el desarrollo urbano y el uso de suelo, ya que esta dimensión forma parte de la institucionalidad territorial y su caracterización permite evaluar sus impactos en el sector transporte. La metodología se compone de las siguientes etapas:

i) Identificar todas las agencias públicas que participan en las políticas de transporte y desarrollo urbano, reconociendo sus objetivos, competencias y escalas de intervención.

ii) Categorizar las agencias de acuerdo con la clasificación de gobernanza multinivel, según la cual existen instituciones tipo I, que corresponden a escalas de gobierno con un territorio determinado (gobierno nacional, regional, metropolitano, local, entre otros); e instituciones tipo II, que corresponden a organizaciones con un objeto específico y transversales a las escalas territoriales (agencias que coordinan concesiones, protegen el medioambiente, entre otras).

iii) Precisar la participación y atribuciones de las agencias sobre diferentes ámbitos de las políticas de transporte y desarrollo urbano. Para ello, se utilizan las siguientes dimensiones:

a. Ámbito de acción: transporte público, vialidad, gestión de la demanda, seguridad vial, modos no motorizados, y desarrollo urbano y uso de suelo.

b. Función de las políticas: planificación (proyección y planeamiento normativo sobre el desarrollo del territorio), inversión (financiamiento y construcción de proyectos) y gestión (operación y mantención).

Para su aplicación a Santiago, se consideró como área metropolitana el territorio que comprende las 40 comunas que forman un continuo de construcciones urbanas y cumplen criterios de funcionalidad, de acuerdo con el último informe elaborado por las autoridades oficiales. ${ }^{2}$ Luego, para identificar y categorizar las agencias públicas que inciden en ella, se revisó la documentación oficial y se validó con entrevistas semiestructuradas a miembros antiguos o vigentes de algunas agencias. Finalmente, se realizó una revisión bibliográfica de las principales observaciones y análisis ya realizados a la gobernanza de transporte urbano de Santiago. El grueso de ellas se encuentra en las recomendaciones de organismos internacionales (Organización para la Cooperación y el Desarrollo Económicos [ocDE], 2013, 2017), los informes de tres comisiones presidenciales realizadas en la última década ${ }^{3}$

2 Este corresponde al documento de trabajo "Metodología para determinar Áreas Funcionales de las Ciudades Chilenas", elaborado por el Instituto Nacional de Estadísticas (INE), el Ministerio de Vivienda y Urbanismo (Minvu) y la Secretaría de Planificación de Transporte (seCtra) (2019).

3 Estas corresponden a la Política Nacional de Desarrollo Urbano (Programa de Naciones Unidas para el Desarrollo [PNUD] \& Ministerio de Vivienda y Urbanismo [Minvu], 2014), la Comisión Asesora Presidencial Pro-Movilidad Urbana (2014) y la Comisión Asesora Presidencial en Descentralización y Desarrollo Regional (2014). 
y trabajos académicos, informes y consultorías que han abordado esta problemática, directa o indirectamente (Aravena et al., 2013; Arenas, 2007; CIs Consultores, 2005; Consejo Nacional de Desarrollo Urbano [CNDU], 2017; Correa, 2010, 2015; Figueroa \& Orellana, 2007; Orellana, 2009; Sagaris \& Landon, 2017). El propósito de la revisión es sintetizar el diagnóstico y articularlo con los resultados anteriores, evaluando cómo responden a la caracterización de la gobernanza y a la literatura sobre diseños institucionales y políticas de transporte.

Es importante mencionar que tanto la caracterización de la gobernanza de Santiago de Chile, como la revisión, análisis y discusión posterior, no consideran los cambios y reformas que se realizarán en el marco del proceso de descentralización regional a partir del año 2021, con la elección democrática de los gobernadores regionales y el establecimiento de un mecanismo de transferencia de competencias.

\section{Resultados}

Diseños institucionales y políticas de transporte

En la Tabla 2 se sintetiza una revisión general de los beneficios y costos de la integración de las agencias públicas al interior de las áreas metropolitanas.

TABLA 2 Beneficios y costos de la integración entre agencias públicas

\begin{tabular}{|c|c|c|}
\hline & BENEFICIOS & costos \\
\hline Eficiencia & $\begin{array}{l}\text { Permite mayores aprendizajes e } \\
\text { innovación }\end{array}$ & $\begin{array}{l}\text { Costos de transacción } \\
\text { Pérdida de recursos y especialización }\end{array}$ \\
\hline Equidad & $\begin{array}{l}\text { Considera externalidades entre } \\
\text { sectores }\end{array}$ & \\
\hline Coherencia & $\begin{array}{l}\text { Evita puntos ciegos } \\
\text { Favorece una comprensión multidi- } \\
\text { mensional de los problemas }\end{array}$ & \\
\hline Legitimidad & $\begin{array}{l}\text { Podría permitir interlocutores } \\
\text { territoriales }\end{array}$ & \\
\hline Accountability & Evita duplicación de funciones & $\begin{array}{l}\text { Dificulta el establecimiento de los } \\
\text { responsables }\end{array}$ \\
\hline
\end{tabular}

FUENTE: ELABORACIÓN PROPIA A PARTIR DE RODE ET AL. (2008), STEAD Y MEIJERS (2009) y OECD (2OI 5 )

Se observa que la integración de las agencias públicas tendría beneficios en múltiples dimensiones, pero que a su vez podría implicar algunos costos en su eficiencia (asociados a la transacción y a la pérdida de especialización) y accountability (dificulta establecer sus responsables). Sin embargo, la evidencia indica que es esencial que las diferentes agencias de transporte urbano presenten grados de integración (Monzón, 2005; OECD, 2015; Rode et al., 2008). Sus beneficios superarían largamente los costos, debido a características específicas de las políticas de transporte, entre las que se encontrarían:

i. Las externalidades existentes entre las diferentes políticas de transporte. Un ejemplo ilustrativo es la distribución de la vialidad: dado que las ciudades 
cuentan con un espacio limitado disponible para la movilidad, priorizar suelo para ciertos modos de transporte tiene directas consecuencias sobre los otros; de esta forma, la coordinación entre agencias públicas que abordan distintos modos permitiría internalizar estos impactos.

ii. La inexistencia de grados de integración generaría políticas que procuren mejorar las velocidades de viaje de cada modo de transporte por separado (Rode et al., 2008). Este enfoque institucional beneficiaría directamente a la automovilidad, que monopolizaría el espacio vial disponible (oeCD, 2015) y afectaría la equidad entre los territorios, en detrimento de las comunidades con peor acceso al sistema de transporte (Martens, 2016).

Algo similar ocurriría entre las políticas de transporte y desarrollo urbano, donde la evidencia también revela la necesidad de que sus agencias alcancen ciertos grados de integración (Legacy et al., 2012; Monzón, 2005; Mu \& De Jong, 2016; oecD, 2015; Rode et al., 2008). Entre las razones para justificar ello, se encontrarían:

i. Las interacciones entre las decisiones de movilidad y localización. Los costos de transporte dependen de la longitud de los recorridos, razón por la cual se vinculan directamente con la localización de la vivienda y de las actividades; a su vez, las decisiones de localización están influenciadas por la accesibilidad y externalidades que ofrecen los distintos puntos de la ciudad.

ii. La inexistencia de grados de integración entre sus agencias afectaría la eficiencia y coherencia de las políticas, ya que estas abordarían los síntomas urbanos (como la congestión vehicular, desregulación urbana) y no los orígenes de los problemas. De esta forma se subestimarían las consecuencias de la construcción de vialidad, la suburbanización o expansión urbana, y cómo estas incrementan las distancias de viaje, el consumo de energía o las emisiones de carbono (oECD, 2015; Rode et al., 2008).

Respecto de la conveniencia de la centralización o descentralización del poder y competencias, la Tabla 3 presenta una revisión general de los beneficios de cada alternativa.

Se observa que tanto la centralización como la descentralización tendrían asociados múltiples efectos en las áreas metropolitanas. En términos de eficiencia, existiría un trade-off entre la cercanía al territorio -que mejora la información y la flexibilidad e integración de las agencias- y una mayor distancia, por las economías de escala y juegos suma cero. En cuanto a la equidad, los beneficios dependerían de si ella se entiende como redistribución y consideración de las externalidades (centralización), o como el respeto a la proporcionalidad de su generación de recursos en cada territorio (descentralización). La coherencia está asociada a la articulación entre la escala funcional (del problema) y administrativa (de la solución), por lo que podría mejorar ante ambos procesos. Luego, la legitimidad podría mejorar directamente con la descentralización (mayor proximidad), pero podría empeorar ante un mayor clientelismo. Por último, el accountability debiera mejorar a menores escalas, ya que facilita la rendición de cuentas, pero la centralización a su vez favorecería el control institucional. 
TABLA 3 Beneficios de la centralización y descentralización según los criterios de evaluación

\begin{tabular}{|c|c|c|}
\hline $\begin{array}{l}\text { CRITERIOS DE } \\
\text { EVALUACIÓN }\end{array}$ & CENTRALIZACIÓN & DESCENTRALIZACIÓN \\
\hline Eficiencia & $\begin{array}{l}\text { Permite mayores economías de } \\
\text { escala } \\
\text { Evita juegos suma cero entre } \\
\text { territorios }\end{array}$ & $\begin{array}{l}\text { Proximidad al problema } \\
\text { Favorece flexibilidad e integración } \\
\text { de las agencias }\end{array}$ \\
\hline Equidad & $\begin{array}{l}\text { Considera las externalidades entre } \\
\text { jurisdicciones } \\
\text { Permite redistribución de recursos } \\
\text { entre territorios }\end{array}$ & $\begin{array}{l}\text { Respeto a la proporcionalidad en } \\
\text { la generación de recursos de cada } \\
\text { territorio }\end{array}$ \\
\hline Coherencia & $\begin{array}{l}\text { Puede articular entre escala funcio- } \\
\text { nal y administrativa } \\
\text { Favorece el interés público }\end{array}$ & $\begin{array}{l}\text { Puede articular entre escala funcio- } \\
\text { nal y administrativa } \\
\text { Favorece el pluralismo de intereses }\end{array}$ \\
\hline Legitimidad & Evita clientelismo & $\begin{array}{l}\text { Mejora la deliberación y participa- } \\
\text { ción ciudadana }\end{array}$ \\
\hline Accountability & $\begin{array}{l}\text { Favorece el control instituciona- } \\
\text { lizado }\end{array}$ & Mejora la rendición de cuentas \\
\hline
\end{tabular}

Así, la aplicación de estos criterios para recomendar políticas de transporte urbano resulta ambivalente. Por un lado, existen razones y evidencia que apoyan su centralización. Las políticas de transporte tendrían ciertas economías de escala ${ }^{4}$ (Monzón, 2005; OECD, 2015) y externalidades entre las distintas jurisdicciones ${ }^{5}$ (Bird \& Slack, 2005). Una mayor centralización evitaría también una desigualdad de niveles del servicio de transporte entre jurisdicciones, derivada de las asimetrías en la generación de recursos (OECD, 2015). También se vería favorecido el interés público, impidiendo que jurisdicciones de menores escalas defiendan los servicios de transporte de sus propios ciudadanos, generando externalidades en los territorios colindantes.

Por otro lado, existen razones para evitar una centralización excesiva de las políticas de transporte, pues se perdería proximidad a la realidad territorial y se debilitaría la participación ciudadana. Mayores escalas implicarían también una mayor rigidez de las agencias, lo que dificultaría la posibilidad de conseguir grados de integración entre ellas y con otras políticas sectoriales.

En este contexto, con diferentes dimensiones en juego, una parte importante de la literatura citada afirma que la escala adecuada para planificar, invertir y gestionar el transporte urbano sería justamente el área metropolitana. A este nivel correspondería la escala funcional, es decir, el límite que permite internalizar las externalidades y

4 Bird y Slack (2005) argumentan que centralizar el transporte implica una baja de costos unitarios, pero mantiene o eleva los costos totales, debido a que armoniza los niveles de servicio, por lo que la mejora en la eficiencia no sería tal.

5 El ejercicio que proponen Marsden y Rye (2010) sobre este punto es sugerente: si se considera un viaje de A а B: ¿̨a qué territorio se le imputa la externalidad? ¿A la región desde donde se realiza el viaje (región A)? ¿Al lugar de destino (región B)? ¿A las regiones en ruta? 
enfrentar integralmente los problemas y desafíos de transporte. En el nivel metropolitano se alcanzarían suficientes economías de escala, se podría considerar las externalidades entre las jurisdicciones locales, se focalizarían los recursos en las zonas que cuentan con peor servicio y se podría realizar una mejor rendición de cuentas (considerando que los problemas son transversales a toda la ciudad).

Estructura y caracterización de la gobernanza de transporte en Santiago de Chile Dentro del entramado institucional chileno, las agencias relacionadas a las políticas urbanas y de transporte se agrupan en distintos ministerios sectoriales. Estos corresponden a grandes instituciones sectoriales, dependientes del nivel central, que reúnen una serie de divisiones y agencias públicas. En la Tabla 4 se encuentran los ministerios que inciden en el área metropolitana de Santiago en temas de transporte y desarrollo urbano, y el resumen detallado de sus competencias asociadas.

\section{TABLA 4 Descripción de los ministerios sectoriales}

\begin{tabular}{|l|l|}
\hline \multicolumn{1}{|c|}{ MINISTERIO } & \multicolumn{1}{c|}{\begin{tabular}{c}
\multicolumn{1}{c|}{ COMPETENCIAS GENERALES EN TRANSPORTE } \\
Y DESARROLLO URBANO
\end{tabular}} \\
\hline $\begin{array}{l}\text { Ministerio de Transportes } \\
\text { y Telecomunicaciones } \\
\text { (MTT) }\end{array}$ & $\begin{array}{l}\text { Planificación y ejecución de políticas de transporte } \\
\text { Supervisión de empresas públicas y privadas que operen me- } \\
\text { dios de transporte } \\
\text { Control del cumplimiento de leyes, reglamentos y normas de } \\
\text { transporte }\end{array}$ \\
\hline $\begin{array}{l}\text { Ministerio de Obras } \\
\text { Públicas (MOP) }\end{array}$ & $\begin{array}{l}\text { Planificación, inversión y regulación de infraestructura pública } \\
\text { Regulación de concesiones privadas }\end{array}$ \\
\hline $\begin{array}{l}\text { Ministerio de Vivienda y } \\
\text { Urbanismo (MINvu) }\end{array}$ & $\begin{array}{l}\text { Desarrollo de políticas habitacionales, espacios públicos y áreas } \\
\text { verdes } \\
\text { Planificación urbana } \\
\text { Inversión y ejecución de vialidad urbana }\end{array}$ \\
\hline $\begin{array}{l}\text { Ministerio de Medio } \\
\text { Ambiente (MAA) }\end{array}$ & $\begin{array}{l}\text { Evaluación ambiental de las políticas urbanas y de transporte } \\
\text { Elaboración de planes de descontaminación y control de } \\
\text { emisiones }\end{array}$ \\
\hline
\end{tabular}

FUENTE: ELABORACIÓN PROPIA A PARTIR DE DOCUMENTOS OFICIALES Y ENTREVISTAS

Cada ministerio cuenta con una agencia coordinadora a nivel regional, llamada Secretaría Regional Ministerial (sERemi), por lo que en el Gran Santiago cada ministerio cuenta con su propia SEREMI correspondiente. Adicionalmente, varios ministerios cuentan con una serie de agencias sectoriales (tipo II) que tienen alguna participación en las políticas de transporte, cuyo detalle se puede encontrar en la Tabla 5. 
TABLA 5 | Descripción de las agencias sectoriales

\begin{tabular}{|c|c|c|c|}
\hline AGENCIA & DEPENDENCIA & ESCALAS & ATRIBUCIONES \\
\hline $\begin{array}{l}\text { Directorio de Trans- } \\
\text { porte Público Metro- } \\
\text { politano (DTPM) }\end{array}$ & MTT & Metropolitana & $\begin{array}{l}\text { Planificación, coordinación y regula- } \\
\text { ción de las licitaciones de operación } \\
\text { del transporte público } \\
\text { Planificación de infraestructura para } \\
\text { transporte público }\end{array}$ \\
\hline $\begin{array}{l}\text { Unidad de Control } \\
\text { de Tránsito (Uост) }\end{array}$ & MTT & $\begin{array}{l}\text { Nacional } \\
\text { Regional }\end{array}$ & $\begin{array}{l}\text { Monitoreo de condiciones de tránsito } \\
\text { Gestión de sistemas de control de } \\
\text { tránsito }\end{array}$ \\
\hline $\begin{array}{l}\text { Secretaría de Planifi- } \\
\text { cación de Transporte } \\
\text { (sECTRA) }\end{array}$ & MTT & $\begin{array}{l}\text { Nacional } \\
\text { Regional }\end{array}$ & $\begin{array}{l}\text { Planificación de sistemas de transporte } \\
\text { urbano } \\
\text { Evaluación social de políticas de } \\
\text { transporte }\end{array}$ \\
\hline \begin{tabular}{|l|} 
Comisión Nacional \\
de Seguridad de \\
Tránsito (CONASET) \\
\end{tabular} & MTT & $\begin{array}{l}\text { Nacional } \\
\text { Regional }\end{array}$ & $\begin{array}{l}\text { Planificación de normativas de seguri- } \\
\text { dad de tránsito } \\
\text { Evaluación de la seguridad de tránsito }\end{array}$ \\
\hline Fiscalización & MTT & $\begin{array}{l}\text { Nacional } \\
\text { Regional }\end{array}$ & $\begin{array}{l}\text { Control del cumplimiento de la } \\
\text { normativa de transportes en seguridad } \\
\text { y calidad }\end{array}$ \\
\hline Metro de Santiago & Presidencia & Metropolitana & $\begin{array}{l}\text { Planificación y operación de las líneas } \\
\text { de trenes urbanos }\end{array}$ \\
\hline $\begin{array}{l}\text { Empresa de Ferroca- } \\
\text { rriles del Estado (EFE) }\end{array}$ & Presidencia & $\begin{array}{l}\text { Nacional } \\
\text { Regional }\end{array}$ & $\begin{array}{l}\text { Planificación y operación de las líneas } \\
\text { de trenes suburbanos }\end{array}$ \\
\hline $\begin{array}{l}\text { Dirección Gral. de } \\
\text { Concesiones }\end{array}$ & MOP & $\begin{array}{l}\text { Nacional } \\
\text { Regional }\end{array}$ & $\begin{array}{l}\text { Planificación y gestión de proyectos } \\
\text { de vialidad interurbana y urbana } \\
\text { (autopistas) }\end{array}$ \\
\hline $\begin{array}{l}\text { Dirección de Planea- } \\
\text { miento (DIRPLAN) }\end{array}$ & MOP & $\begin{array}{l}\text { Nacional } \\
\text { Regional }\end{array}$ & $\begin{array}{l}\text { Planificación y coordinación de las } \\
\text { políticas de infraestructura vial }\end{array}$ \\
\hline $\begin{array}{l}\text { Dirección de Via- } \\
\text { lidad }\end{array}$ & MOP & Regional & $\begin{array}{l}\text { Inversión y gestión de la infraestruc- } \\
\text { tura vial }\end{array}$ \\
\hline $\begin{array}{l}\text { Servicio de Vivienda } \\
\text { y Urbanización } \\
\text { (sERviu) }\end{array}$ & MINVU & Regional & $\begin{array}{l}\text { Inversión y gestión de vialidad y obras } \\
\text { urbanas }\end{array}$ \\
\hline $\begin{array}{l}\text { División de Desarro- } \\
\text { llo Urbano (DDU) }\end{array}$ & MINVU & Nacional & $\begin{array}{l}\text { Planificación de las políticas nacionales } \\
\text { de desarrollo urbano }\end{array}$ \\
\hline $\begin{array}{l}\text { Parque Metropoli- } \\
\text { tano }\end{array}$ & MINVU & Metropolitana & $\begin{array}{l}\text { Mantención de los principales parques } \\
\text { urbanos }\end{array}$ \\
\hline Carabineros & $\begin{array}{l}\text { Ministerio del } \\
\text { Interior }\end{array}$ & \begin{tabular}{|l|} 
Nacional \\
Regional \\
Local
\end{tabular} & $\begin{array}{l}\text { Fiscalización del cumplimiento de } \\
\text { normas de tránsito y de emisiones }\end{array}$ \\
\hline
\end{tabular}

FUENTE: ELABORACIÓN PROPIA A PARTIR DE DOCUMENTOS OFICIALES Y ENTREVISTAS

Por último, se tienen agencias territoriales o tipo I, que intervienen en el territorio:

i. Gobierno Regional (GORE): dependiente casi totalmente del gobierno central, ya que se compone por la Intendencia, cuya autoridad es designada por el Presidente de la República, y el Consejo Regional, compuesto por consejeros elegidos por votación directa en periodos de cuatro ańos. Entre sus atribuciones relacionadas con el transporte y desarrollo urbano se encuentra la aprobación del Plan Regulador Metropolitano de Santiago (PRMS), que regula las densidades, uso de suelo y límite urbano y cuya elaboración SEREMI del MINVU; y la 
administración de los fondos de inversión regional, que pueden ser utilizados para financiar proyectos de transporte o espacios públicos.

ii. Municipios: corresponden a los gobiernos locales de la ciudad. Tienen autonomía política y administrativa, ya que sus autoridades son elegidas democráticamente. Sus atribuciones relacionadas con el transporte son el control de tránsito; la inversión y mantenimiento de la vialidad local, espacios peatonales y ciclovías; y la planificación urbana local a través de los Planes Reguladores Comunales (PRC).

Como síntesis, un esquema de las agencias que intervienen en el área metropolitana de Santiago relacionadas con el transporte y desarrollo urbano se encuentra en la Figura 1.

FIGURA I | Esquema de la gobernanza de transporte en Santiago de Chile

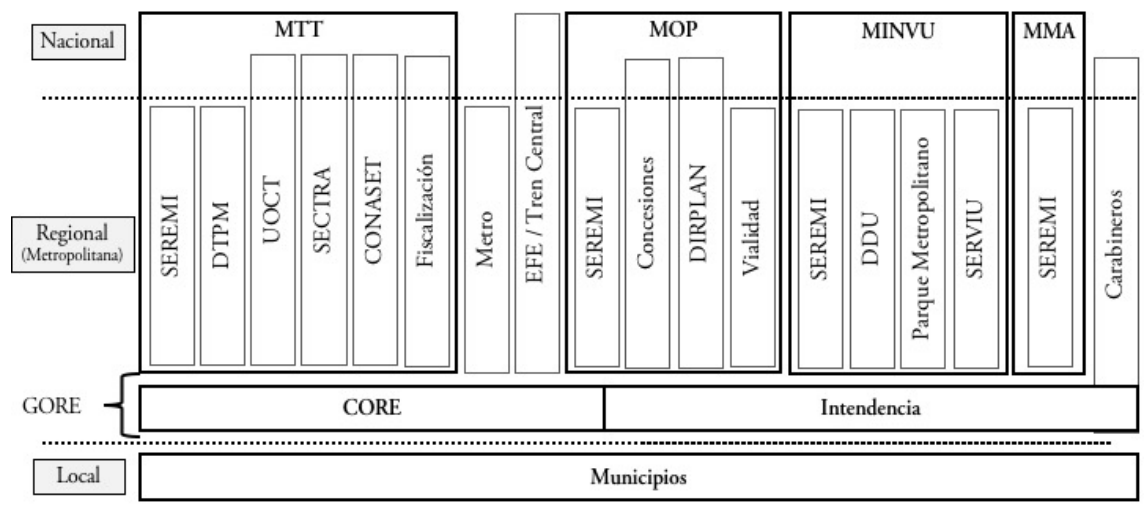

FUENTE: ELABORACIÓN PROPIA

Luego, se tiene la matriz de observación de la gobernanza a partir de las dimensiones propuestas en la metodología. Se obtienen así los resultados presentados en la Tabla 6, desde la perspectiva de los ámbitos de acción, y en la Tabla 7, desde la perspectiva de las agencias. 
TABLA 6 Matriz de ámbitos de acción y función

\begin{tabular}{|c|c|c|c|}
\hline & PLANIFICACIÓN & INVERSIÓN & GESTIÓN \\
\hline $\begin{array}{l}\text { Transporte } \\
\text { público }\end{array}$ & $\begin{array}{l}\text { DTPM: planes de recorridos e } \\
\text { infraestructura para buses } \\
\text { SECTRA: plan maestro de } \\
\text { transporte público } \\
\text { Metro: planes de extensión } \\
\text { de la red de trenes urbanos } \\
\text { EFE: planes de extensión de } \\
\text { la red de trenes suburbanos }\end{array}$ & $\begin{array}{l}\text { Metro: construcción de } \\
\text { líneas de trenes urbanos y } \\
\text { estaciones intermodales } \\
\text { DTPM: inversión en infraes- } \\
\text { tructura para buses } \\
\text { Tren Central: construc- } \\
\text { ción de servicios de trenes } \\
\text { suburbanos } \\
\text { Dir. Gral. de Concesiones: } \\
\text { concesión de algunos corre- } \\
\text { dores de buses } \\
\text { SERVIU: construcción de } \\
\text { infraestructura para buses }\end{array}$ & $\begin{array}{l}\text { DTPM: regulación de opera- } \\
\text { dores de buses y gestión del } \\
\text { medio de pago } \\
\text { Metro: operación de los } \\
\text { trenes urbanos } \\
\text { Tren Central: operación de } \\
\text { los trenes suburbanos }\end{array}$ \\
\hline Vialidad & $\begin{array}{l}\text { DIRPLAN: plan de infraes- } \\
\text { tructura } \\
\text { SERVIU: plan de vialidad } \\
\text { urbana } \\
\text { SECTRA: plan maestro de } \\
\text { infraestructura vial }\end{array}$ & $\begin{array}{l}\text { GORE: inversión en vialidad } \\
\text { prioritaria } \\
\text { SERVIU: construcción de } \\
\text { vialidad urbana } \\
\text { Dirección de Vialidad: cons- } \\
\text { trucción de vialidad urbana } \\
\text { Dir. Gral. de Concesiones: } \\
\text { concesiones de infraestruc- } \\
\text { tura vial (autopistas urbanas) } \\
\text { Municipios: construcción de } \\
\text { vialidad local }\end{array}$ & $\begin{array}{l}\text { SERVIU, Dirección de Viali- } \\
\text { dad, Dirección General de } \\
\text { Concesiones y Municipios: } \\
\text { mantención de vialidad }\end{array}$ \\
\hline $\begin{array}{l}\text { Gestión de } \\
\text { demanda }\end{array}$ & $\begin{array}{l}\text { UOCT: plan de sistemas de } \\
\text { control } \\
\text { SECTRA: análisis de iniciati- } \\
\text { vas de gestión de demanda } \\
\text { SEREMI (MMA): planes de } \\
\text { descontaminación }\end{array}$ & & $\begin{array}{l}\text { UОст: operación de sistemas } \\
\text { de control del tráfico } \\
\text { Municipios: control del } \\
\text { tránsito } \\
\text { Carabineros: control y } \\
\text { restricciones de tránsito } \\
\text { SEREMI (MTT): control de } \\
\text { apertura y cierre de vialidad }\end{array}$ \\
\hline $\begin{array}{l}\text { Seguridad } \\
\text { vial }\end{array}$ & $\begin{array}{l}\text { CONASET: planes y normas } \\
\text { de seguridad vial }\end{array}$ & $\begin{array}{l}\text { Dirección de Vialidad: insta- } \\
\text { lación de medidas y señales } \\
\text { Municipios: construcción } \\
\text { de medidas de seguridad } \\
\text { vial (lomos de toro, zonas } \\
\text { 30, etc.) }\end{array}$ & $\begin{array}{l}\text { Carabineros: control de } \\
\text { cumplimiento de normas de } \\
\text { tránsito } \\
\text { Fiscalización: control de } \\
\text { cumplimiento de normas de } \\
\text { transporte }\end{array}$ \\
\hline $\begin{array}{l}\text { Modos no } \\
\text { motorizados }\end{array}$ & $\begin{array}{l}\text { SECTRA: plan de infraes- } \\
\text { tructura de modos no } \\
\text { motorizados } \\
\text { Municipios: planes de peato- } \\
\text { nalización y ciclovías }\end{array}$ & $\begin{array}{l}\text { GORE: administración de } \\
\text { fondos de inversión regional } \\
\text { SERVIU: construcción de } \\
\text { infraestructura para modos } \\
\text { no motorizados } \\
\text { Municipios: inversión en } \\
\text { peatonalización y ciclovías }\end{array}$ & $\begin{array}{l}\text { Municipios: mantenimiento } \\
\text { de espacios peatonales y } \\
\text { ciclovías }\end{array}$ \\
\hline $\begin{array}{l}\text { Desarrollo } \\
\text { urbano y uso } \\
\text { de suelo }\end{array}$ & $\begin{array}{l}\text { DDU: planes nacionales de } \\
\text { desarrollo urbano } \\
\text { SEREMI (MINVU): elaboración } \\
\text { PRMS } \\
\text { GORE: aprobación PRMS } \\
\text { Municipios: PRC }\end{array}$ & $\begin{array}{l}\text { GORE: administración de } \\
\text { fondos de inversión regional } \\
\text { SERVIU: construcción de } \\
\text { espacio público, áreas verdes } \\
\text { y equipamiento urbano } \\
\text { Municipios: construcción de } \\
\text { espacio público, áreas verdes } \\
\text { y equipamiento urbano local }\end{array}$ & $\begin{array}{l}\text { Parque Metropolitano: man- } \\
\text { tención de grandes parques } \\
\text { urbanos } \\
\text { Municipios: mantención de } \\
\text { parques y espacios públicos } \\
\text { locales }\end{array}$ \\
\hline
\end{tabular}

FUENTE: ELABORACIÓN PROPIA 


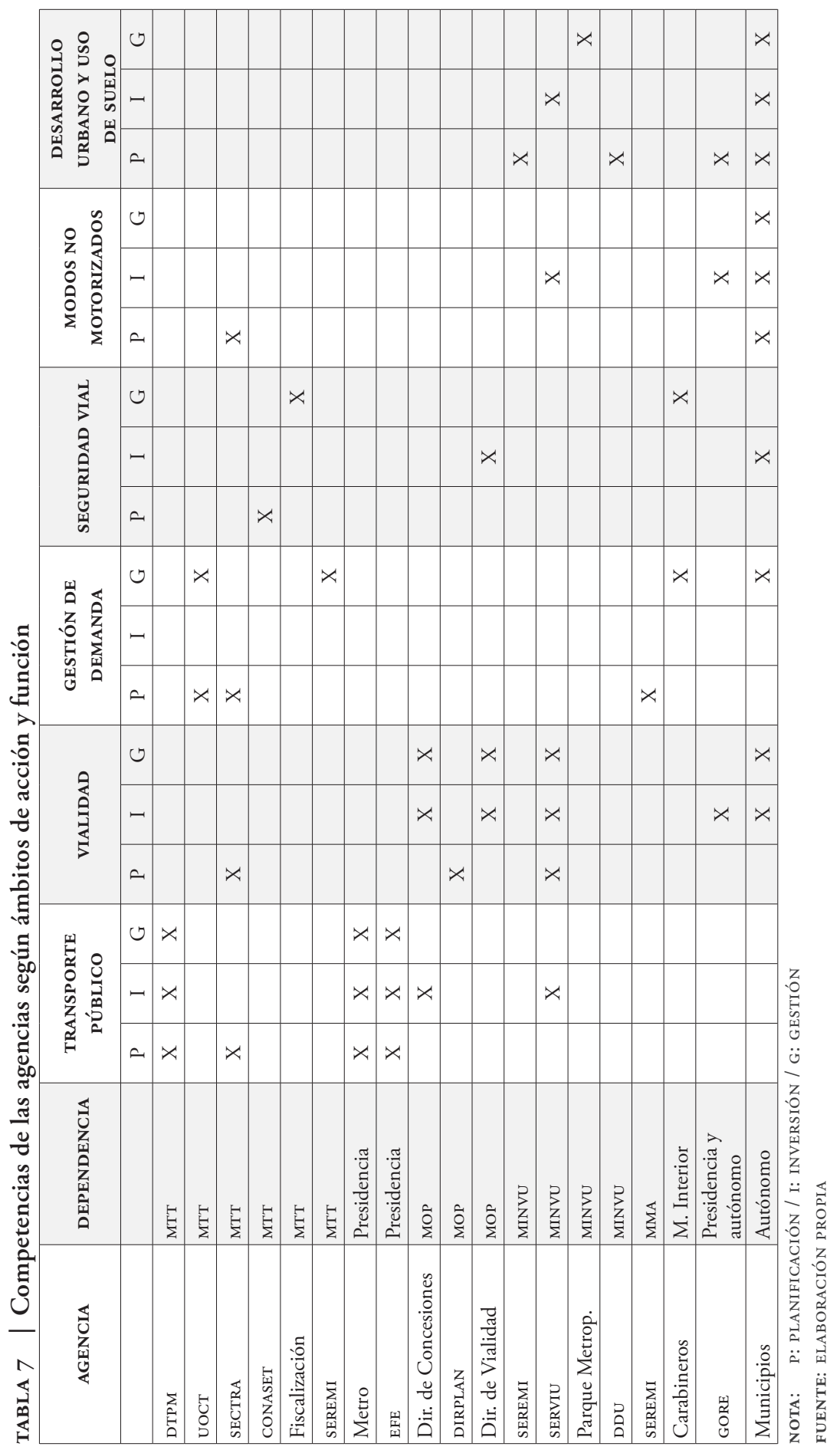


Realizando un ejercicio equivalente al de Rode et al. (2008), en la Figura 2 se tiene una representación de la distribución de poder y competencias en las diferentes escalas de gobierno según sus funciones y ámbitos de acción. Este diagrama indica si una escala de gobierno tiene o no atribuciones, si su responsabilidad es mayor o menor y si existe una dependencia política con respecto a una escala de gobierno superior.

FIGURA 2 Distribución de poder y competencias entre niveles de gobierno según funciones y ámbitos de acción

Mayores competencias Menores competencias Dependencia
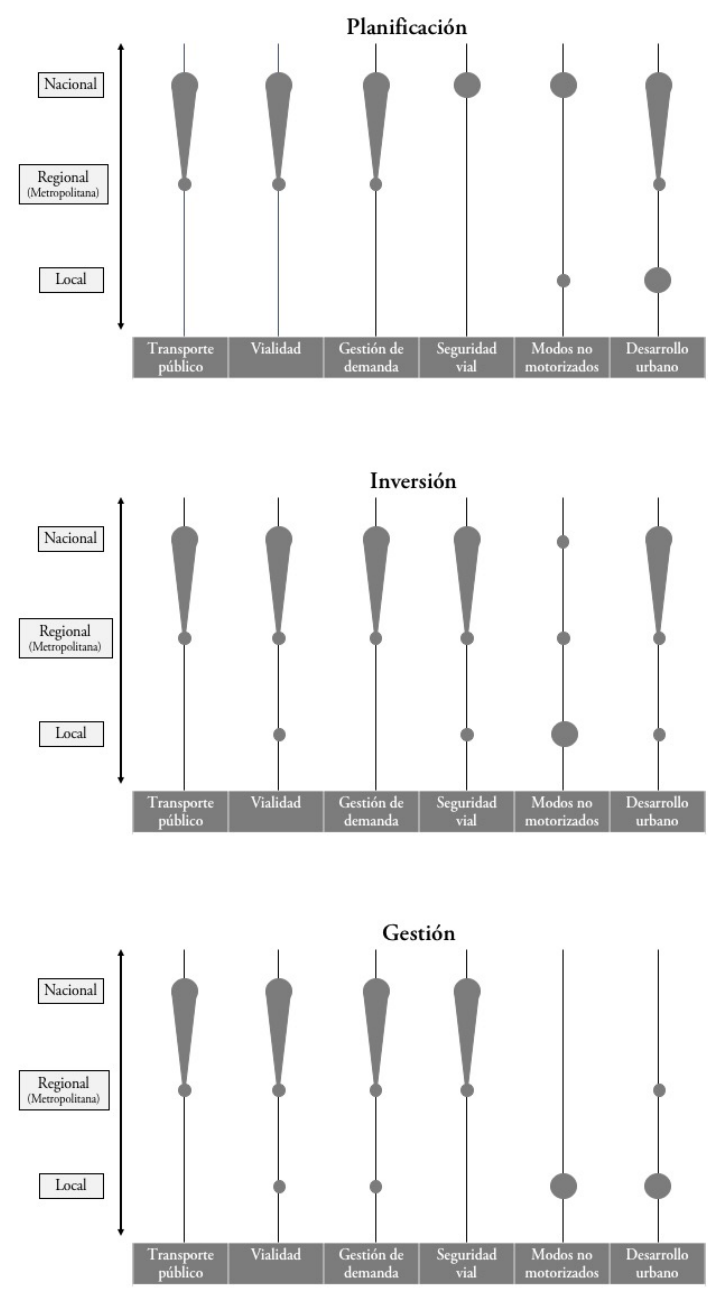

FUENTE: ELABORACIÓN PROPIA A PARTIR DE RODE ET AL. (2008) 


\section{Observaciones y análisis sobre la gobernanza de transporte urbano en Santiago de Chile}

De acuerdo con la revisión bibliográfica realizada, el diseño institucional en torno al transporte urbano en Santiago de Chile se caracterizaría principalmente por tres elementos: i) centralización de poder y competencias; ii) dispersión y especialización de funciones; y iii) fragmentación del territorio urbano.

En primer lugar, existe cierto consenso en que la institucionalidad chilena concentra las funciones y atribuciones en el gobierno central, y que ello se agudiza para la gobernanza urbana y de transporte. Este diagnóstico ha sido manifestado en los tres informes de las comisiones presidenciales convocadas en la última década y ha dado paso a una serie de reformas ${ }^{6}$ con el propósito de darle autonomía política y administrativa a los GORE, cuya implementación todavía no entra en régimen.

La caracterización de la gobernanza de transporte de Santiago de Chile aquí realizada aporta evidencia a este diagnóstico. Como se observa en la Figura 2, la gran mayoría de los ámbitos de acción del transporte son principalmente competencia de agencias sectoriales dependientes del nivel central. Aun cuando algunas agencias estén desconcentradas a una escala regional (como las SEREMIS, SERVIU o la Dirección de Vialidad), igualmente tienen una dependencia directa del gobierno nacional, es decir, implementan las directrices de los ministerios en materias urbanas y de transporte, por lo que son estos los que finalmente toman las decisiones y definen su presupuesto. ${ }^{7}$ Una posible excepción corresponde a las políticas sobre modos no motorizados y parte del desarrollo urbano, donde tanto los GORE como los municipios tienen atribuciones para planificar, invertir y mantener espacios públicos, ciclovías, áreas verdes o espacios peatonales. Los municipios, por otra parte, tienen también autonomía para realizar la planificación urbana de su comuna.

Los diseños institucionales con centralización de poder y competencias, como se profundizó en la primera sección de resultados, tienen consecuencias en el desempeño de las políticas de transporte. Ellas se pueden agrupar de acuerdo con los criterios de evaluación:

i. Eficiencia: por un lado, las agencias sectoriales se habrían mostrado efectivas para conseguir sus objetivos específicos, como la ejecución presupuestaria o la materialización de obras. Sin embargo, las políticas urbanas y de transporte también perderían eficacia, debido a su distanciamiento de los problemas y del territorio y la rigidez de las agencias por sus tamaños y escalas, lo que dificulta su coordinación o cooperación (Aravena et al., 2013; ocDE, 2013, 2017).

ii. Legitimidad: la concentración de competencias en el gobierno central habría dificultado la participación ciudadana y la aprobación de las políticas de

$6 \quad$ Estas corresponden a las leyes $\mathrm{N}^{\circ} 21073$ y N² 21074 promulgadas el año 2018, que establecen la elección democrática de los gobernadores regionales para el año 2021 y un mecanismo de transferencia de competencias del nivel central a los GORE.

7 Lo anterior se refleja, por ejemplo, en que el gasto local y regional autónomo con respecto al total del presupuesto nacional en Chile se encontraría entre el 14 y $17 \%$, en comparación con la mayoría de los países de la ocDe (2017), donde corresponde a un mínimo de 30\%. Esto se agudiza al considerar la inversión en infraestructura, donde el $88 \%$ de ella se prioriza en el nivel central, lo cual es muy superior al 44\% correspondiente al promedio de los países de la oCDE. 
transporte por parte de los ciudadanos y la sociedad civil. Figueroa y Orellana (2007) evidencian un ejemplo de ello: la implementación del nuevo sistema de transporte público (Transantiago) en 2007 tuvo importantes problemas de comprensión y aprobación en la ciudadanía, junto con desarrollarse con oposición directa de los gobiernos locales. Sagaris y Landon (2017), de otra parte, cuestionan la incapacidad de las agencias sectoriales para articularse adecuadamente con la ciudadanía y sociedad civil a propósito de la construcción de las autopistas urbanas.

Un segundo diagnóstico transversal sobre la gobernanza urbana y de transporte en Santiago sería la existencia de una multiplicidad de agencias y la dispersión de funciones. Esto implicaría que las distintas competencias y ámbitos de acción estarían desagregados en diversas agencias públicas, cada una preocupada del cumplimiento de metas y objetivos específicos.

La simple observación de la caracterización realizada a la gobernanza de transporte de Santiago (Tabla 6) permite notar que múltiples agencias tienen las mismas competencias. Se advierte, por ejemplo, que son cinco las agencias que participan en la inversión de distintos tipos de vialidad en Santiago (serviu, Vialidad, Concesiones, Municipios y GORE) o que la planificación de transporte público se realiza en distintas instituciones (DTPM para buses, Metro para sus extensiones o nuevas líneas y SECTRA para el transporte en general). La realización de un solo proyecto de transporte público podría requerir: i) la planificación y aprobación de la agencia evaluadora (SECTRA); ii) coordinación entre operadores (DTPM, EFE y Metro); iii) colaboración con la Dirección General de Concesiones, en el caso de que sea concesionado, o con SERVIU, en el caso de que sea construido; iv) cooperación con UOCT para solicitar una reconfiguración de semáforos; y v) largas negociaciones con los municipios en el caso de que se vean afectados.

Esta dispersión de funciones, a su vez, genera impactos en las políticas de transporte urbano, que se pueden agrupar de acuerdo con los criterios de evaluación:

i. Eficiencia: la especialización de las agencias sectoriales favorecería el cumplimiento de sus propios objetivos; sin embargo, también dificultaría la capacidad de interacción, coordinación y cooperación entre ellas (cIs Consultores, 2005; ocDE, 2017). Existen ejemplos documentados de ello (OCDE, 2013): dificultades en la coordinación de caminos municipales e intermunicipales entre Vialidad y SERVIU, en la cooperación y priorización del transporte público entre la DTPM y la UOCT, y en la coordinación de cualquier intervención del espacio vial y público repartido entre diferentes agencias (Concesiones, sERviU, Vialidad o municipios). De esta forma, este escenario de dispersión y especialización favorece la compartimentación y entorpece la eficacia de las políticas complejas e intersectoriales de transporte urbano (Comisión Promovilidad, 2014).

ii. Coherencia: tanto la dispersión como la especialización en las instituciones tiende a generar puntos ciegos en la gobernanza, afectando la coherencia. Esto impide una comprensión multidimensional de los problemas de transporte, ya que cada agencia pública se preocupa de su propio objetivo sectorial (Comisión Promovilidad, 2014; Correa, 2010). Dado que la planificación no se realiza de forma estratégica e integrada, ya que la planificación de SECTRA 
no es vinculante, los objetivos de cada agencia pueden no coincidir e incluso pueden ser contradictorios entre sí (CNDU, 2017). Ello se agudizaría cuando las agencias responden a diferentes ministerios, que pueden actuar de acuerdo con criterios diferentes sobre las mismas materias (ocDE, 2017). La OCDE (2013) sugiere un ejemplo de ello: mientras SECTRA (МтT) evalúa y propone medidas con el enfoque de desincentivar la demanda por transporte privado mediante un mejor transporte público, por su parte, Concesiones (MOр) promueve la construcción de autopistas urbanas e infraestructura vial. Ante las dificultades para darles coherencia a las políticas de transporte, la articulación entre ellas y la planificación urbana se vuelven prácticamente inexistentes.

iii. Accountability: la multiplicidad de agencias daría pie a una mayor yuxtaposición de competencias, ya que muchas agencias públicas terminan realizando funciones similares, por lo que existirían dificultades para rendir cuentas y esclarecer las responsabilidades (Arenas, 2007; CIs Consultores, 2005; OCDE, 2013). Un ejemplo de ello podrían ser las responsabilidades en torno a la congestión: no hay claridad sobre cuál es la agencia pública (las que planifican, las que invierten en vialidad o las involucradas en transporte público) que debe dar cuenta de los avances en este problema y hacerse responsable.

Una tercera y última observación general sobre la gobernanza de transporte de Santiago pone acento en la inexistencia de una unidad político-administrativa que abarque toda el área metropolitana. Bajo el gobierno central se encuentran los 40 municipios, lo que implica una fragmentación territorial de la ciudad. Por otra parte, los municipios suelen ser reacios a formas de colaboración, la que en el caso de transporte se vuelve más difícil, pues no existen instancias de asociatividad (ocDE, 2013).

La caracterización de la gobernanza en Chile evidencia que tanto las agencias sectoriales como el GORE son dependientes del gobierno central, por lo que las únicas entidades autónomas tipo I insertas en la ciudad son los gobiernos locales. Este escenario institucional también tiene consecuencias que se pueden agrupar en los criterios de evaluación:

i. Equidad: en aquellos ámbitos de acción donde exista participación de los municipios, podrán existir diferencias en la provisión de servicios derivadas de las desigualdades de ingresos, que en Santiago pueden ser hasta cinco o seis veces per cápita entre municipios (Larraín, 2020). Esto se manifestaría, por ejemplo, en la disponibilidad de ciclovías y espacios peatonales, o diferencias en la calidad del espacio público y áreas verdes. Aunque el gobierno central, a través de sus agencias sectoriales (como el SERVIU), tenga competencias en estos ámbitos de acción, asumiría que la primera responsabilidad es de los municipios y no compensaría adecuadamente la inequidad urbana. La desigualdad de ingresos entre municipios, por otra parte, generaría una asimetría de poder entre territorios (Orellana, 2009) y dificulta que los municipios más pobres atraigan proyectos urbanos o de transporte, ya que no podrían asumir los costos de su mantención (Aravena et al., 2013).

ii. Coherencia: el espacio territorial sobre el cual se piensan las políticas de transporte serían las comunas y no la ciudad (Correa, 2015), lo que dificulta la realización de proyectos a una escala intermunicipal o municipal. Por otra parte, 
cada municipio respondería a sus propios ciudadanos, por lo que se opondrían a aquellas políticas de transporte que tengan externalidades sobre su territorio pero que beneficien el interés público.

\section{Discusión}

Las categorías de evaluación presentadas muestran ser útiles para comprender la complejidad de los efectos tanto de la integración de las agencias públicas como de la distribución de competencias entre las escalas de gobierno. Todos los posibles diseños institucionales afectan el desempeño de las políticas de transporte en alguna dimensión, por lo que se requiere ser conscientes de los beneficios y costos en términos económicos, sociales y políticos de cada uno de ellos.

En cualquier caso, la evidencia de la conveniencia de la integración entre las agencias para el caso de transporte es concluyente: son considerables los beneficios de planificar, invertir y gestionar integradamente las diferentes políticas, tanto intersectorialmente como vinculándolas al desarrollo urbano y el uso de suelo. La caracterización de la gobernanza de transporte urbano en Santiago de Chile refleja de buena forma estas dinámicas. La variedad de agencias y la dispersión y especialización de las competencias tiene como consecuencia una multiplicación de las interacciones, que dificulta la posibilidad de constituir grados de integración. Este trabajo permite aproximarse a cómo esta forma de gobernanza sectorial afecta las políticas de transporte en su eficiencia, coherencia y accountability.

Una eventual reforma a la institucionalidad de transporte de Santiago debe considerar algunos de estos elementos. Aunque la elaboración de propuestas requiere una mayor profundidad, se sugiere: i) planificar con una sola visión conceptual, desde una agencia tipo SECTRA pero vinculante en el financiamiento y gestión de las políticas; ii) formular paquetes de medidas de políticas de transportes, que incorporen y articulen distintos ámbitos: transporte público, vialidad, gestión de la demanda y modos no motorizados; iii) vincular los planes de transporte con los instrumentos de planificación de suelo metropolitanos (como el PRMs), estableciendo objetivos estructurantes y metas compartidas; y iv) realizar una gestión intersectorial del transporte, en especial de los sistemas de transporte público, que permita integrar flujos de información y sistemas de control para toda el área metropolitana.

Por cierto, estas ideas no requieren de la fusión de las diversas agencias de transporte y desarrollo urbano en los niveles superiores de gobierno; de hecho, la gobernanza conjunta y centralizada puede tornarse más complicada y sobrecargar a las autoridades. ${ }^{8}$ De esta forma, se tiene que una integración efectiva entre las políticas de transporte y desarrollo urbano conlleva necesariamente un reordenamiento de

Dos experiencias son evidencia de lo anterior: i) en Chile, durante el gobierno de Ricardo Lagos (2000-2006) se nombró un ministro para que se hiciera cargo de las carteras de Obras Públicas y de Transportes y Telecomunicaciones. En 2006, el gobierno de Michelle Bachelet terminó con este modelo; ii) en Reino Unido, 1997, el gobierno laborista de Tony Blair creó el Department of the Environment, Transport and the Regions para sustituir al Departamento de Medio Ambiente, el Ministerio de Agricultura, Pesca y Alimentación y el Departamento de Transporte, pero finalmente fue disuelto en 2001 . 
los poderes y competencias entre las distintas escalas de gobierno. En ese marco, la revisión de literatura de este trabajo indica que la centralización y descentralización tienen efectos contradictorios en los criterios de evaluación. Por una parte, la centralización podría generar economías de escala, internalizar las externalidades territoriales, redistribuir para promover la equidad, favorecer el interés público y no el de territorios particulares, evitar el clientelismo y favorecer el control institucional, entre otros beneficios. Por otro, la descentralización permitiría una mayor proximidad al problema, mayor flexibilidad e integración entre las agencias, mejor rendición de cuentas y fortalecería la deliberación y participación ciudadana.

En términos de escalas, la caracterización de la gobernanza de transporte en Santiago muestra que en ella se manifiestan dos fenómenos que parecen contradictorios, pero que se complementan: centralización y fragmentación territorial. La centralización es posible por la existencia de múltiples agencias tipo II que inciden en distintas escalas, pero que dependen finalmente del gobierno nacional y sus ministerios. Los GORE, única agencia pública tipo I que intermedia con la escala local, también dependen políticamente del nivel central y tienen casi nulas atribuciones en transporte y desarrollo urbano. Esta concentración del poder en el nivel central impactaría las políticas de transporte tanto en su eficiencia (generaría "problemas de información”) y su legitimidad (dificultaría la articulación territorial y participación ciudadana). Al mismo tiempo, se tiene un escenario de fragmentación territorial, con más de una treintena de gobiernos locales en el área metropolitana de Santiago, lo que afectaría la equidad territorial y la coherencia de las políticas de transporte.

La evidencia indica que la escala adecuada para la planificación, gestión e inversión del transporte urbano es la metropolitana, ya que resuelve mejor las tensiones de los procesos de descentralización y centralización. Por un lado, permite suficientes economías de escala y una mayor coherencia entre la escala funcional (del problema) y administrativa (de la solución), superando la fragmentación territorial. Por otro, es una escala con una mayor proximidad al territorio que el nivel central, lo que mejora la legitimidad de las políticas y la rendición de cuentas sobre los planes y programas.

La aplicación de un modelo de autoridad metropolitana de transporte tiene una serie de complejidades que exceden este trabajo. En Chile se intentó crear esta figura institucional para Santiago entre los años 2007 y 2009, a través de un proyecto de ley (Boletín No 5077-15) que finalmente quedó entrampado en su discusión legislativa, ante las dificultades para que algunos ministerios cedieran parte de sus competencias y presupuestos. En esta línea, Busetti (2015) sugiere algunas dinámicas y oportunidades para materializar los cambios institucionales metropolitanos, y el CNDU (2017) ha propuesto algunos caminos posibles para constituir gobiernos metropolitanos en Chile.

De todas formas, se sugieren algunas propuestas que viabilicen una gobernanza metropolitana de transporte: i) realizar una redistribución de funciones que evite una superposición, duplicación o competencia entre las diferentes escalas de gobierno, donde el nivel central focalice sus responsabilidades en la planificación e inversión de infraestructura de transporte con impacto interregional (como los aeropuertos y autopistas interurbanas) y los gobiernos locales en aquellos proyectos de espacio 
público y modos no motorizados con un impacto local; ii) establecer grados de integración vertical ${ }^{9}$ entre los gobiernos nacionales, regionales, metropolitanos y locales, donde las instancias de intervención en cada uno se compatibilicen y coordinen.

\section{Agradecimientos}

Se reconoce y agradece el apoyo del Centro de Estudios Públicos, el Centro de Excelencia en Bus Rapid Transit financiado por vref y del Centro de Desarrollo Urbano Sustentable (CEDEUS), proyecto ANID/FONDAP 15110020.

\section{Referencias bibliográficas}

Aravena, A., De Gregorio, J. \& Poduje, I. (2013). Via rápida para reducir la desigualdad. Propuestas para revertir la segregación urbana en nuestras ciudades. Espacio Público, Informe de Políticas Públicas, 2. https://www.espaciopublico.cl/wp-content/ uploads/2021/05/14.pdf

Arenas, F. (2007). Reconfiguración espacial y adaptación institucional: un reajuste pendiente en el caso de los espacios metropolitanos chilenos. En C. De Mattos \& R. Hidalgo (Eds.), Santiago de Chile: movilidad espacial y reconfiguración metropolitana. Instituto de Geografía Uc, Serie GeoLibros No 8, eure Libros.

Bird, R. \& Slack, E. (2005). Aspectos fiscales de la gobernabilidad metropolitana. En E. Rojas, J. R. Cuadrado-Roura \& J. M. Fernández Güell (Eds.), Gobernar las metrópolis (pp. 263-347). Banco Interamericano de Desarrollo. https://bit.ly/3CjoRpS

Busetti, S. (2015). Governing metropolitan transport: Institutional solutions for policy problems. Springer.

CIs Consultores. (2005). Una autoridad metropolitana de transporte urbano para Santiago. Consultoría realizada para la Subsecretaría de Transportes.

Comisión Asesora Presidencial en Descentralización y Desarrollo Regional. (2014). Propuesta Política de Estado y Agenda para la Descentralización y el Desarrollo Territorial de Chile. https://bit.ly/386OITd

Comisión Asesora Presidencial Pro-Movilidad Urbana (Comisión Promovilidad). (2014). Problemas de movilidad urbana: estrategia y medidas para su mitigación. Santiago, Chile. https://bit.ly/3b9AId3

Consejo Nacional de Desarrollo Urbano (CNDu). (2017). Propuestas para una nueva institucionalidad para la gobernanza urbana. https://bit.ly/2w1zH2k

9 Un buen caso de ello es el que aporta Arenas (2008). Las instituciones tipo il o sectoriales, al no estar previamente definidas en un territorio específico, suelen carecer de interlocutores institucionalizados, dado que se presentan como problemáticas transversales y transterritoriales. Sin embargo, las instituciones tipo I se enfrentan a marcos estructurados y definidos de actuación, como son las instancias de intermediación política. Un nivel de integración adecuado entre ambas permitiría que políticas necesariamente multiescalares -como las acciones para el desarrollo sustentable- y que cuentan con agencias sectoriales logren cierta legitimidad en los territorios a través de la integración con los gobiernos locales o metropolitanos. 
Correa, G. (2010). Transporte y ciudad. Revista EURE - Revista de Estudios Urbano Regionales, 36(107), 133-137. http://dx.doi.org/10.4067/S0250-71612010000100008

Correa, G. (2015). Institucionalidad y gobernanza. Foro Urbano Regional. Santiago, Chile. https://bit.ly/2GdbUW9

Cruz-Muńoz, F. (2021). Patrones de expansión urbana de las megaurbes latinoamericanas en el nuevo milenio. Revista EURE - Revista de Estudios Urbano Regionales, 47(140), 29-49. http://dx.doi.org/10.7764/EURE.47.140.02

De Mattos, C. A. (2001). Movimientos del capital y expansión metropolitana en las economías emergentes Latinoamericanas. Revista de Estudios Regionales, (60), 15-43. https://www. redalyc.org/pdf/755/75506001.pdf

Figueroa, O. (2005). Transporte urbano y globalización: Políticas y efectos en América Latina. Revista EURE - Revista de Estudios Urbano Regionales, 31(94), 41-53. http://dx.doi. org/10.4067/S0250-71612005009400003

Figueroa, O. \& Orellana, A. (2007). Transantiago: gobernabilidad e institucionalidad. Revista EURE - Revista de Estudios Urbano Regionales, 33(100), 165-171. http://dx.doi. org/10.4067/S0250-71612007000300010

Giménez-Capdevila, R. (2005). Organización de los transportes e institucionalización de las áreas metropolitanas en Europa occidental. En C. De Mattos (Ed.), Gobernanza, competitividad y redes: La gestión en las ciudades del siglo XXI (pp. 505-515). Instituto de Estudios Urbanos y Territoriales, Pontificia Universidad Católica de Chile.

Giménez-Capdevila, R. (2008). Gobernanza multinivel y política de transportes en Europa. En G. Yáńez, A. Orellana, O. Figueroa \& F. Arenas (Eds.), Ciudad, poder, gobernanza. Instituto de Geografía UC, Colección RIDEAL, Serie GeoLibros Nº 9, Eure Libros.

Kübler, D. \& Heinelt, H. (2004). Metropolitan governance, democracy and the dynamics of place. En H. Heinelt \& D. Kübler (Eds.), Metropolitan Governance in the 21st Century: Capacity, Democracy and the Dynamics of Place (pp. 8-28). Routledge.

Heinrichs, D., Nuissl, H. \& Rodríguez Seeger, C. (2009). Dispersión urbana y nuevos desafíos para la gobernanza (metropolitana) en América Latina: el caso de Santiago de Chile. Revista EURE - Revista de Estudios Urbano Regionales, 35(104), 29-46. http://dx.doi. org/10.4067/S0250-71612009000100002

Hooghe, L. \& Marks, G. W. (2001). Multi-level governance and European integration. Rowman \& Littlefield.

Instituto Nacional de Estadísticas (INE), Ministerio de Vivienda y Urbanismo (MINVU) \& Secretaría de Planificación de Transporte (sectra), Chile. (2019). Metodología para determinar Areas Funcionales de las Ciudades Chilenas. https://bit.ly/2Vi0u8k

Jaimurzina, A. (2018). Gobernanza del transporte: perspectivas teóricas y de políticas. Boletín $F A L, \mathrm{~N}^{\circ} 365$. Comisión Económica para América Latina y el Caribe (CEPAL). http://hdl. handle.net/11362/44310

Klein, J. L. \& Tremblay, D. G. (2010). Social actors and their role in metropolitan governance in Montréal: towards an inclusive coalition. GeoJournal, 75(6), 567-579. http://dx.doi. org/10.1007/s10708-009-9270-0

Klink, J. (2005). Perspectivas recientes sobre la organización metropolitana. Funciones y gobernabilidad. En E. Rojas, J. R. Cuadrado-Roura \& J. M. Fernández Güell (Eds.), Gobernar las metrópolis (pp. 127-191). Banco Interamericano de Desarrollo. https:// bit.ly/3CjoRpS 
Larraín, C. (2020). El financiamiento de los municipios en Chile. Punto de referencia CEP. https://cutt.ly/vhUmqE2

Lefèvre, C. (1998). Metropolitan government and governance in western countries: a critical review. International Journal of Urban and Regional Research, 22(1), 9-25. https://doi. org/10.1111/1468-2427.00120

Lefèvre, C. (2005). Gobernabilidad democrática de las áreas metropolitanas. Experiencias y lecciones internacionales para las ciudades latinoamericanas. En E. Rojas, J. R. Cuadrado-Roura \& J. M. Fernández Güell (Eds.), Gobernar las metrópolis (pp. 195261). Banco Interamericano de Desarrollo. https://bit.ly/3CjoRpS

Legacy, C., Curtis, C. \& Sturup, S. (2012). Is there a good governance model for the delivery of contemporary transport policy and practice? An examination of Melbourne and Perth. Transport Policy, 19(1), 8-16. https://doi.org/10.1016/j.tranpol.2011.07.004

Letelier, L. (2012). Teoría y práctica de la descentralización fiscal. Ediciones uc.

Marsden, G. \& Reardon, L. (2017). Questions of governance: Rethinking the study of transportation policy. Transportation Research Part A: Policy and Practice, 101, 238225. https://doi.org/10.1016/j.tra.2017.05.008

Marsden, G. \& Rye, T. (2010). The governance of transport and climate change. Journal of transportgeography, 18(6), 669-678. http://dx.doi.org/10.1016/j.jtrangeo.2009.09.014

Martens, K. (2016). Transport justice: Designing fair transportation systems. Routledge.

Monzón, A. (2005). Gestión del transporte metropolitano. En E. Rojas, J. R. CuadradoRoura \& J. M. Fernández Güell (Eds.), Gobernar las metrópolis (pp. 409-472). Banco Interamericano de Desarrollo. https://bit.ly/3CjoRpS

Moscoso, M., van Laake, T., Quiñones, L. M., Pardo, C. F. \& Hidalgo, D. (Eds.). (2020). Sustainable Urban Transport in Latin America: assessment and recommendations for mobility policies. Despacio. Bogotá, Colombia. https://www.despacio.org/wp-content/ uploads/2020/02/SUTLac-05022020-web.pdf

Mu, R. \& De Jong, M. (2016). A network governance approach to transit-oriented development: Integrating urban transport and land use policies in Urumqi, China. Transport Policy, 52, 55-63. https://doi.org/10.1016/j.tranpol.2016.07.007

Organisation for Economic Co-operation and Development (OECD). (2015). Governing the city. OeCD Publishing.

Organización para la Cooperación y el Desarrollo Económicos (OCDE). (2013). Estudios de politica urbana de Chile. OECD Publishing.

Organización para la Cooperación y el Desarrollo Económicos (OCDE). (2017). Brechas y estándares de gobernanza de la infraestructura pública en Chile: Análisis de Gobernanza de Infraestructura. Éditions OCDE. http://dx.doi.org/10.1787/9789264286948-es

Orellana, A. (2009). La gobernabilidad metropolitana de Santiago: la dispar relación de poder de los municipios. Revista EURE - Revista de Estudios Urbano Regionales, 35(104), 101120. http://dx.doi.org/10.4067/S0250-71612009000100005

Programa de Naciones Unidas para el Desarrollo (PNUD) \& Ministerio de Vivienda y Urbanismo (minvu), (Chile). (2014). Política Nacional de Desarrollo Urbano. Vol. 4. Santiago, Chile. https://bit.ly/3jv7bO0 
Riffo, L. (2008). Relacionalidad y re-escalamiento: tensiones emergentes para la gobernanza territorial. En G. Yáńez, A. Orellana, O. Figueroa \& F. Arenas (Eds.), Ciudad, poder, gobernanza (pp. 53-66). Instituto de Geografía uc, Colección RIdEAL, Serie geoLibros $\mathrm{N}^{\circ}$ 9, EURE Libros.

Rode, P. (2019). Urban planning and transport policy integration: The role of governance hierarchies and networks in London and Berlin. Journal of Urban Affairs, 41(1), 39-63. https://doi.org/10.1080/07352166.2016.1271663

Rode, P., Wagner, J., Brown, R., Chandra, R., Sundaresan, J., Konstantinou, C., Tesfay, N. \& Shankar, P. (2008). Integrated city making: Governance, planning and transport. LSE Cities, London School of Economics and Political Science.

Rodríguez, A. \& Oviedo, E. (2001). Gestión urbana y gobierno de áreas metropolitanas. CEPAL, Serie Medio Ambiente y Desarrollo 34. https://repositorio.cepal.org/bitstream/ handle/11362/5718/1/S01040367_es.pdf

Rojas, E., Cuadrado-Roura, J. R. \& Fernández Güell, J. M. (Eds.). (2005). Gobernar las metrópolis. Banco Interamericano de Desarrollo. https://bit.ly/3CjoRpS

Sagaris, L. \& Landon, P. (2017). Autopistas, ciudadanía y democratización: la Costanera Norte y el Acceso Sur, Santiago de Chile (1997-2007). Revista EURE - Revista de Estudios Urbano Regionales, 43(128), 127-151. http://dx.doi.org/10.4067/S025071612017000100006

Sánchez, J.-E. (2008). Gobernanza desde la óptica del poder y las escalas. En G. Yáñez, A. Orellana, O. Figueroa \& F. Arenas (Eds.), Ciudad, poder, gobernanza (pp. 21-52). Instituto de Geografía uc, Colección RIDEAL, Serie GeoLibros Nº 9, eUre Libros.

Slack, E. (2007). Managing the coordination of service delivery in metropolitan cities: The role of metropolitan governance. The World Bank.

Stead, D. \& Meijers, E. (2009) Spatial Planning and Policy Integration: Concepts, Facilitators and Inhibitors. Planning Theory \& Practice, 10(3), 317-332. https://doi. org/10.1080/14649350903229752

Suazo-Vecino, G., Muñoz, J. C. \& Fuentes Arce, L. (2020). The displacement of Santiago de Chile's downtown during 1990-2015: travel time effects on eradicated population. Sustainability, 12(1), 289. https://doi.org/10.3390/su12010289

Veeneman, W., Augustin, K., Enoch, M., d'Arcier, B. F., Malpezzi, S. \& Wijmenga, N. (2015). Austerity in public transport in Europe: The influence of governance. Research in Transportation Economics, 51, 31-39. https://doi.org/10.1016/j.retrec.2015.07.005

Veeneman, W. \& Mulley, C. (2018). Multi-level governance in public transport: Governmental layering and its influence on public transport service solutions. Research in Transportation Economics, 69, 430-437. https://doi.org/10.1016/j.retrec.2018.07.005

Yáñez, G., Orellana, A., Figueroa, O. \& Arenas, F. (Eds.). (2008). Ciudad, poder, gobernanza. Instituto de Geografía UC, Colección RIDEAL, Serie GeoLibros Nº 9, eUre Libros. 